\title{
PERAN PT PERMODALAN NASIONAL MADANI (PT PNM) DALAM PEMBIAYAAN PELAKU USAHA AGRIBISNIS DI KOTA TARAKAN
}

\section{THE ROLE OF PT PERMODALAN NASIONAL MADANI (PT PNM) IN AGRIBUSINESS BUSINESS FINANCING IN TARAKAN CITY}

\author{
Sekar Inten Mulyani ${ }^{1)}$, Afnan ${ }^{2)}$ \\ 1,2) Fakultas Pertanian, Universitas Borneo Tarakan \\ Jl. Amal Lama No. 01, Tarakan, Kalimantan Utara \\ Email: inten131313@gmail.com
}

\begin{abstract}
ABSTRAK
Lembaga ULaMM mendukung pembiayaan pelaku usaha di Kota Tarakan sejak tahun 2016 sampai sekarang telah melayani 99 pelaku usaha diberbagai bidang usaha jasa dan barang. Pelaku usaha dibidang agribisnis yang terlayani sebanyak 30 nasabah yang memiliki usaha di bidang subsistem hilir agribisnis. Tujuan penelitian ini: 1) Mengetahui peranan PT PNM bagi pelaku usaha agribisnis di Kota Tarakan, 2) Mengetahui persepsi pelaku usaha terhadap layanan PT PNM di Kota Tarakan, dan 3). Menganalisis faktor-faktor yang mempengaruhi persepsi nasabah pada pelayanan PT PNM. Penelitian ini dilaksanakan di Kota Tarakan dengan objek kajian di Unit Layanan Modal Mikro (ULaMM) PT. Permodalan Nasional Madani (PNM). Waktu Penelitian Bulan September - Desember 2019. Responden ditentukan dengan mengunakan metode purposive sampling dengan pertimbangan pada penentuan kriteria responden, diambil sebanyak 30 responden yang merupakan nasabah ULaMM yang bergerak disektor usaha agribisnis. Analisis data yang digunakan untuk tujuan pertama dengan metode deskriptif kualitatif. Sedangkan tujuan kedua Mengetahui persepsi pelaku usaha terhadap layanan PT PNM di Kota Tarakan. Faktor - faktor yang mempengaruhi persepsi nasabah dianalisis menggunakan regresi berganda melalui aplikasi SPSS sehingga dapat diketahui seberapa besar pengaruh $\left(R^{2}\right)$ kualitas layanan (tangible, realibility, responsiveness, assurance dan emphaty). Hasil menunjukan peranan PT PNM bagi pelaku usaha di Kota Tarakan adalah sebagai lembaga pembiayaan modal usaha dan memberikan bimbingan serta pelatihan bagi nasabah PT PNM. Persepsi nasabah terhadap kualitas layanan PT PNM di kota Tarakan $97 \%$ menyatakan kualitas layanan yang diberikan dalam kategori baik. Faktor-faktor yang mempengaruhi persepsi kualitas pelayanan memiliki R2 sebesar $97,1 \%$ dan secara parsial $\times 1, \times 2, \times 3, \times 4$ dan $\times 5$ berpengaruh signifikan terhadap $\mathrm{Y}$.
\end{abstract}

\section{Kata Kunci : Peran; Persepsi; Pelayanan}

\begin{abstract}
ULaMM Institute supports the financing of business actors in the city of Tarakan since 2016 until now has served 99 business actors in various fields of service and goods. Businessmen in the field of agribusiness are served by as many as 30 customers who have a business in the area of downstream agribusiness subsystem. Objectives of this research: 1) know the role of PT PNM for agribusiness Enterprises in Tarakan City, 2) know the perception of business actors on the service of PT PNM in the city of Tarakan, and 3). Analyzing the factors that influence the customer's perception on the Ministry of PT PNM. This research was conducted in Tarakan city with the object of study in capital service Unit Micro (ULaMM) PT. Permodalan Nasional Madani (PNM). Research time in
\end{abstract}


September - December 2019. Respondents were determined by using the Purposive sampling method with consideration on determining the criteria of respondents, taken as many as 30 respondents who are ULaMM customers who move the agribusiness business. Data analysis is used for first purpose with qualitative descriptive methods. While the second objective to know the perception of business actors in the service of PT PNM in Tarakan City. Factors that influence customer perception are analyzed using multiple regression through SPSS application so it can be known how big (R2) quality of service (tangible, realibility, responsiveness, assurance and Emphaty). Results showed the role of PT PNM for business actors in Tarakan City is as a business capital financing institution and provide guidance and training for customers of PT PNM. Customer perception of the quality of service of PT PNM in the city of Tarakan $97 \%$ expressed the quality of service provided in good category. Factors affecting the perception of service quality have R2 of $97.1 \%$ and partially $\times 1, \times 2, X 3, X 4$ and $X 5$ significantly against $Y$.

\section{Keywords: Role; Perception; Service}

\section{PENDAHULUAN}

Kota Tarakan merupakan salah satu wilayah yang penuh dengan aktifitas layanan jasa dan perdagangan. Disamping itu juga Kota Tarakan ini berpotensi pada sektor perikanan dan pertanian baik budidaya maupun hasil olahan pertanian itu sendiri. Dalam sistem agribisnis lembaga keuangan menjadi subsistem penunjang yang berperan dalam penyediaan modal bagi pelaku usaha terutama usaha yang bergerak di sector agribisnis. PT Permodalan Nasional Madani (PT PNM) melalui Unit Layanan Modal Mikro (UlaMM) memberikan pelayanan pinjaman modal kepada para pelaku UMKM baik disektor produksi maupun jasa dengan bunga yang terjangkau. Lembaga ULaMM mendukung pembiayaan pelaku usaha di Kota Tarakan sejak tahun 2016 sampai sekarang telah melayani 99 pelaku usaha diberbagai bidang usaha jasa dan barang. Pelaku usaha dibidang agribisnis yang terlayani sebanyak 30 nasabah yang memiliki usaha di bidang subsistem hilir agribisnis. Lembaga pembiayaan ini memiliki peran sebagai penyedia modal bagi usaha ekonomi terutama untuk UMKM sekaligus memberikan pendampingan dalam manajemen usaha melalui pelatihan - pelatihan yang diberikan UlaMM kepada nasabahnya.

Tujuan penelitian ini adalah :

1) Mengetahui peranan PT PNM bagi pelaku usaha agribisnis di Kota Tarakan

2) Mengetahui persepsi pelaku usaha terhadap layanan PT PNM di Kota Tarakan

3) Menganalisis faktor-faktor yang mempengaruhi persepsi nasabah pada pelayanan PT PNM

\section{METODE PENELITIAN}

Penelitian ini dilaksanakan di Kota Tarakan dengan objek kajian di Unit Layanan Modal Mikro (ULaMM) PT. Permodalan Nasional Madani (PNM).

\section{a. Teknik Pengambilan Responden}

Responden dalam penelitian ini ditentukan dengan mengunakan metode purposive sampling dengan pertimbangan pada penentuan kriteria responden. Responden dalam penelitian ini terbagi atas dua sebagai berikut :

Informan kunci (key informan), yaitu mereka yang mengetahui dan memeiliki berbagai informasi pokok yang diprlukan dalam penelitian ini. Informan kunci yang digunakan dalam penelitian ini berjumlah dua orang yakni :

a.Kepala Unit Layanan Modal Mikro Kota Tarakan 
b.Kepala bagian pembiayan dan pelatihan pada Unit Layanan Modal Mikro Kota Tarakan.

Informan utama, yaitu responden yang ditentukan dengan mengunakan metode proposive sampling dengan pertimbagan kriteria responden sebagai berikut :
a. Pernah
mengambil
atau mendapatkan modal dari lembaga UlaMM
b. Usaha yang dijalankan minimal 1 (satu) tahun beroperasi
c. Usaha yang dijalankan berbasis Agribisnis

Berdasarkan kriteria tersebut, jumlah pelaku usaha yang akan menjadi reponden dalam penelitian ini sebanyak 30 orang.

\section{b. Teknik Pengambilan Data}

Pengumpulan data dalam penelitian ini menggunakan Metode, observasi, wawancara, dokumentasi.

Menurut Juliansyah (2012) menyatakan bahwa: Observasi adalah Teknik ini menuntut adanya pengamatan dari penulis baik secara langsung maupun tidak langsung terhadap objek penelitian". Obervasi dilakukan dalam penelitian ini untuk mengetahui gambaran awal secara umum terkait dengan Unit Layanan Modal Mikro Kota Tarakan.

Menurut Sugiyono (2015) menyatakan bahwa Wawancara merupakan salah satu teknik pengumpulan data yang dapat dilakukan secara langsung berhadapan dengan yang diwawancarai". Wawancara dalam penelitian ini dilakukan pada pegawai UlaMM untuk mendapatkan informasi tentang unit layana mdal mikto dan pelaku usaha untuk mengetahu persepsi palaku usaha terhadap unit layanan modal mikro kota tarakan. Teknik dokumentasi merupakan catatan peristiwa yang sudah berlaku. Dokumen merupakan pelengkap dari penggunaan metode observasi dan wawancara dalam penelitian kualitatif. Dalam penelitian ini pengumpulan data dengan cara dokumentasi dalam bentuk foto pada objek yang di teliti.

\section{c. Teknik Analisis Data}

Analisis data yang digunakan untuk tujuan pertama adalah dengan metode deskriptif kualitatif. Dengan menggambarkan peranan PT PNM bagi pelaku usaha agribisnis di Kota Tarakan. Sedangkan pada tujuan kedua Mengetahui persepsi pelaku usaha terhadap layanan PT PNM di Kota Tarakan menggunakan metode deskriptif kuantitatif.

Analisis data yang yang digunakan dalam penelitian ini berasal dari hasil gradasi kuesioner dengan menggunakan skala likert. Menurut Sugiyono (2015) Skala Likert merupakan alat untuk mengukur sikap, pendapat, dan persepsi seseorang atau sekelompok orang tentang fenomena sosial. Dengan skala Likert, maka variabel yang akan diukur dijabarkan menjadi indikator variabel. Kemudian indikator tersebut dijadikan sebagai titik tolak untuk menyusun item-item instrumen yang dapat berupa pernyataan atau pertanyaan". Skala ini menggunakan rentang nilai (skor) 1 sampai 5 dengan alternatif jawaban mulai dari Sangat Tidak Baik (1), Tidak Baik (2), Cukup Baik (3), Baik (4) dan Sangat Baik (5).

Metode yang digunakan dalam menentukan atau menilai kualitas jasa layanan adalah metode Serivice Quality (Servqual). Kualitas layanan merupakan faktor kunci yang akan menjadi keunggulan daya saing di dunia perbankan saat ini. Metode pengukuran kualitas layanan yang biasa digunakan untuk mengukur kualitas pada perbankan konvensional serta banyak digunakan secara luas adalah metode SERVQUAL Metode SERVQUAL didasarkan pada lima dimensi yaitu 
tangible, reliability, responsiveness, assurance, dan empathy. (Cahyani, 2016). klasifikasi kategori masing masing variable kualitas layanan dan kualitas layanan secara keseluruhan seperti table dibawah ini :

Tabel 1. Kategori Persepsi Nasabah terhadap Tingkat Pelayanan Unit Layanan Modal Mikro Kota Tarakan

\begin{tabular}{ccl}
\hline No & Interval Kelas & Kualitas Layanan \\
\hline 1 & $20-35$ & Sangat tidak baik \\
2 & $36-51$ & Tidak baik \\
3 & $52-67$ & Cukup baik \\
4 & $68-83$ & Baik \\
5 & $84-100$ & Sangat baik \\
\hline
\end{tabular}

Faktor - faktor yang mempengaruhi persepsi nasabah dianalisis menggunakan regresi berganda melalui aplikasi SPSS sehingga dapat diketahui seberapa besar pengaruh $\left(R^{2}\right)$ kualitas layanan (tangible, realibility, responsiveness, assurance dan emphaty) terhadap persepsi nasabah ULaMM. Adapun persamaan model regresi berganda dapat dituliskan sebagai berikut :

$Y=a+X 1+X 2+X 3+X 4+X 5+e$ Dimana

$Y=$ Persepsi nasabah

$\mathrm{X} 1=$ Tangible

$\mathrm{X} 2=$ Realibility

$\mathrm{X} 3=$ Responsiveness

$\mathrm{X} 4=$ Assurance

$\mathrm{X} 5$ = Emphaty

\section{HASIL DAN PEMBAHASAN}

Unit Layanan Modal Mikro (ULaMM) adalah salah satu jasa layanan permodalan yang dikeluarkan oleh PT. Pemodalan Nasional Madani. Lembaga pembiayaan ini membuka kantor cabang di Tarakan sejak tahun 2016 yang berlokasi di Jl. Sei Berantas Rt. 8 No. 27 Kecamatan Tarakan Timur Kota Tarakan. Unit layanan modal mikro (UlaMM) ini sudah memiliki nasabah yang tentunya adalah pelaku usaha sejak tahun 2017 hingga sekarang sebanyak 99 nasabah dari berbagai jenis usaha..Nasabah yang jenis usahanya bergerak dibidang agribisnis sebanyak 30 nasabah dengan jenis usaha pertanian, peternakan,kehutanan dan perikanan. Dari sisi kegiatan yang dilakukan, selain penyaluran modal kepada pelaku usaha dalam hal ini adalah nasabah, ULaMM juga melakukan bimbingan dan pelatihan sebagai bentuk tindak lanjut dari pembiayaan agar suatu usaha yang dijalankan berkembang dan berkelanjutan.

\section{Peranan PT PNM bagi pelaku usaha agribisnis di Kota Tarakan}

\section{a. Pembiayaan Modal Usaha}

PT PNM melalui Unit Layanan Modal Mikro (ULaMM) memiliki peran strategis bagi pelaku UMKM di Kota Tarakan. Lembaga ini memberikan pembiayaan atau pinjaman modal kepada nasabah sekaligus memberikan pelatihan pelatihan maupun bimbingan yang dibutuhkan bagi nasabah dan berguna bagi pengembangan usahanya. Pembiayaan merupakan salah satu cara yang dapat digunakan untuk menyalurkan modal kepada masyarakat yang ingin mengembangkan usaha yang sedang dijalankan. ULaMM memberikan modal pinjaman antara $\mathrm{Rp}$ $1.000 .000,00$ - Rp 200.000.000,00 dengan suku bunga terjangkau yaitu 0,8 - 1,6 \% setahun. Persyaratan bagi calon nasabah secara umum sebagai berikut : a) Warga negara Indonesia; b)Usaha 
telah berjalan minimal 1 tahun; c)Fotocopi KTP suami istri (bila telah menikah); d)Fotocopi kartu keluarga; e)Fotocopi surat nikah;f) Fotocopi rekening listrik/telepon dan PBB; g)Fotocopi jaminan (SHM/SHGB/SHGU/BPKB/surat kios/akta jual beli) dan $h$ ) Surat keterangan usaha (SKU).

Dengan adanya syarat umum tersebut dan klasifikasi pinjaman untuk nasabah, tentunya Unit Layanan Modal Mikro (UlaMM) membuat sebuah Mekanisme pembiayaan yang terdiri dari 4 tahap yaitu tahap 1 inisiasi yang terdiri dari pengejuan permohonan dana, penerimaan proposal dan pengisian fomilir dan tahap 2 verifikasi yang terdiri dari pengebalian formulir dan survei lokasi dan dilanjutkan dengan tahap 3 Apraisal yang terdiri dari analisis dan penetapan keputusan, serta tahap 4 pengikatan dan pencairan yang terdiri dari penandatanganan surat pernyataan dan pencairan.

\section{b. Bimbingan dan Pelatihan}

Selain memberikan pembiayaan modal usaha, ULaMM juga berperan dalam memberikan bimbingan dan pelatihan pada pelaku usaha UMKM yang menjadi nasabahnya. Bimbingan dan pelatihan yang diberikan bertujuan agar pelakupelaku usaha dapat meningkatkan serta mengembangkan usahanya. Pelatihan dan bimbingan yang diberikan kepada nasabah berupa pelatihan dalam manajemen usaha, pelatihan kemasan produk, informasi pasar dan memberikan motivasi usaha pada nasabah melalui kegiatan diskusi maupun workshop yang diadakan oleh ULaMM. Hal ini sesuai dengan pendapat Layyinaturrobaniyah,(2017) yang menyatakan rendahnya produktivitas ini disinyalir karena rendahnya kualitas sumber daya manusia UMKM khususnya dalam bidang manajemen, organisasi, penguasaan teknologi, dan pemasaran, dan rendahnya kompetensi kewirausahaan UMKM yang relatif masih masih jauh dibandingkan usaha besar. Selain rendahnya produktivitas, UMKM juga diperhadapkan pada terbatasnya akses kepada sumberdaya produktif, terutama terhadap permodalan, teknologi, informasi dan pasar.

\section{Persepsi pelaku usaha terhadap} layanan PT PNM di Kota Tarakan

Persepsi pelaku usaha miko adalah suatu penilaian atau pandangan pelaku usaha mikro dalam hal ini adalah nasabah dari unit layanan modal mikro untuk mellihat sejauh mana tingkat kualitas pelayanan dari unit layanan modal mikro berdasakan beberapa parameter kualitas pelayanan yang meliputi : Tangible, Realibility, Responsiveness, Asurance, Empaty.

Tabel 2. Kategori Tingkat Pelayanan Unit Layanan Modal Mikro Kota Tarakan

\begin{tabular}{clccl}
\hline No & Interval Kelas & Frekuensi & $\mathbf{\%}$ & Kualitas Layanan \\
\hline 1 & $20-35$ & 0 & 0 & Sangat tidak baik \\
2 & $36-51$ & 0 & 0 & Tidak baik \\
3 & $52-67$ & 1 & 3 & Cukup baik \\
4 & $58-83$ & 29 & 97 & Baik \\
5 & $34-100$ & 0 & 0 & Sangat baik \\
& Jumlah & 30 & 100 & \\
\hline
\end{tabular}

Sumber : Data Primer diolah 2019

Berdasarkan tabel di atas dapat dilihat bahwa, persepsi pelaku usaha mikro agribisnis terhadap pelayanan unit layanan modal mikro adalah baik. 
Jawaban ini dibuktikan bahwa reponden yang menjawab baik sebanyak 29 orang yang merupakan jawaban terbanyak dengan persentasi $97 \%$. Rata-rata nasanah UlaMM memiliki persepsi yang baik terhadap pelayanan lembaga keuangan ini karena didukung oleh kualitas pelayanan yang handal, terjamin,cepat dalam merespon dan memiliki empati terhadap permasalahan yang dihadapi nasabah.Hasil analisis regresi berganda dapat dibuat dalam persamaan berikut $Y=-3,591+$ $1,001 \times 1+1,157 \times 2+1,086 \times 3+0,811 \times 4+$ $1,176 \times 5+e$ dengan nilai koefisien determinasi $\left(R^{2}\right)$ sebesar $97,1 \%$. Secara parsial $\times 1, \times 2, \times 3, \times 4$ dan $\times 5$ berpengaruh signifikan terhadap $Y$. Adapun hasil analisis secara lengkap dapat di lihat pada Tabel 5 sebagai berikut :

Tabel 3. Analisis Regresi Berganda

\begin{tabular}{|c|c|c|c|c|c|}
\hline No & & Variabel & Koefisien & Signifikansi & $\%$ \\
\hline 1 & & Konstanta & $-3,5$ & & \\
\hline 2 & $\mathrm{X} 1$ & & 1,001 & 0,000 & \\
\hline 3 & $\times 2$ & & 1,157 & 0,000 & \\
\hline 4 & X3 & & 1,086 & 0,000 & \\
\hline 5 & $\mathrm{X} 4$ & & 0,811 & 0,000 & \\
\hline 6 & $\times 5$ & & 1,176 & 0,000 & \\
\hline 7 & $\mathrm{R}^{2}$ & & & & 97,1 \\
\hline 8 & Uji $F$ & & & 0,000 & \\
\hline
\end{tabular}

\section{KESIMPULAN}

1. Peran PT PNM melalui Unit Layanan Modal Mikro (UlaMM) bagi nasabah terutama pelaku usaha dibidang agribisnis adalah sebagai sumber pembiayaan usaha atau memberikan pinjaman berubah modal usaha. Selain itu juga memberikan pelatihan dan bimbingan kewirausahaan bagi nasabahnya.

2. Persepsi nasabah terhadap kualitas layanan PT PNM menunjukan $97 \%$ menyatakan pelayanan PT PNM dalam kategori baik karena didukung oleh kualitas pelayanan yang handal, terjamin,cepat dalam merespon dan memiliki empati terhadap permasalahan yang dihadapi nasabah.

3. Faktor -faktor yang berpengaruh terhadap Persepsi konsumen dapat dilihat dari persamaan, $Y=-3,591+$ $1,001 X 1+1,157 X 2+1,086 \times 3+0,811 X$ $4+1,176 \times 5+e$ dengan nilai koefisien determinasi $\left(R^{2}\right)$ sebesar $97,1 \%$.
Secara parsial $x 1, \times 2, x 3, x 4$ dan $\times 5$ berpengaruh signifikan terhadap $Y$.

\section{DAFTAR PUSTAKA}

Cahyani DP, 2016. Tingkat Kepuasan Nasabah Terhadap Kualitas Layanan Perbankan Syariah di Yogyakarta. Jurnal Bisnis dan Manajemen . Vol 6 (2). Hal 151162.

Juliansyah, 2012. Metodologi Penelitian Skripsi, Tesis dan Disertasi Karya Ilmiah. Cetakan Kedua ,Kencana Prenada Media, Jakarta.

Layyinaturrabaniyah dan Muizu, 2017. Pendampingan Pengelolaan Keuangan Usaha Mikro di Desa Purwodadi Barat dan Pasirbungur Kabupaten Subang. Pekbis Jurnal Vol 9 (2) hal $91-103$.

Sugiyono, 2015. Metodologi Penelitian Pendidikan Pendekatan Kuantitatif Kualitatif dan R \& D, Alfabeta, Bandung. 
